\title{
A ECOGRAFIA NO DIAGNÓSTICO DAS LESÕES MÚSCULO-TENDINOSAS DO OMBRO*
}

\author{
Arquimedes Artur Zorzetto ${ }^{1}$, Linei Augusta Brolini Dellê Urban ${ }^{2}$, Christian Bark Liu ${ }^{2}$, \\ Luciano Prevedello ${ }^{3}$, Mauricio Zapparoli ${ }^{3}$, Maria Luiza Amalfi Vitola ${ }^{4}$, Yumi Awamura ${ }^{4}$, \\ Mônica Simeão Pedro ${ }^{4}$, Alessandra Bettega Nascimento ${ }^{4}$
}

\begin{abstract}
Resumo Este estudo propôs-se a revisar os aspectos relevantes da anatomia, técnica de exame e achados de imagens, com o objetivo de auxiliar o radiologista no diagnóstico diferencial frente às afecções músculo-tendinosas do ombro. Foram realizadas 34 ultra-sonografias da região do ombro, no período de janeiro a dezembro de 2001. A avaliação foi realizada com transdutores de alta freqüência $(7,5-10 \mathrm{MHz})$. 0 exame foi normal em $23 \%$ dos pacientes (oito casos). Dos 26 casos alterados, observaram-se oito com ruptura total (30\%), cinco com ruptura parcial $(19 \%)$, dez com tendinopatia $(38 \%)$, um com tendinopatia calcificada $(3 \%)$, um com tenossinovite bicipital ( $3 \%$ ) e um com tendinopatia associada a artrite gotosa (3\%). A falta de experiência e de conhecimento das principais alterações que acometem o ombro é um dos principais pontos limitantes do diagnóstico ultra-sonográfico das lesões do ombro. Portanto, o estudo dessas alterações deve ser realizado amplamente.
\end{abstract}

Unitermos: Ombro; Ultra-sonografia; Manguito rotador.

Abstract Ultrasonography findings of musculotendinous lesions of the shoulder.

The purpose of this study is to review the anatomical structures, ultrasonography examination technique and imaging findings in patients with musculotendinous lesions of the shoulder with the aim of helping the radiologist in the differential diagnosis of these lesions. We performed ultrasonography examinations of the shoulder using high-resolution probes (7.5-10 MHz) in 34 patients from January to December, 2001. The examination was normal in eight patients $(23 \%)$ whereas 26 patients presented abnormalities: eight patients had total rotator cuff tears $(30 \%)$, five had partial rotator cuff $(19 \%)$, ten had tendinopathy $(38 \%)$, one had calcified tendinopathy (3\%), one had biceps tendinitis, one had biceps tendon luxation $(3 \%)$ and one had tendinopathy associated to crystal arthropathy (3\%). The lack of experience and the insufficient knowledge about the main diseases of the shoulder are limiting factors for the diagnosis of these lesions. Therefore, a comprehensive study of the abnormalities of the shoulder should be carried out.

Key words: Shoulder; Ultrasonography; Rotator cuff.

\section{INTRODUÇÃO}

A ultra-sonografia do ombro tem adquirido importância em virtude do seu baixo custo, da facilidade de acesso e da sua flexibilidade $^{(\mathbf{1 , 2})}$. Este estudo propôs-se a revisar os aspectos relevantes da anatomia, técnica de exame e achados de imagens, com o objetivo de auxiliar o radiologista no

* Trabalho realizado no Serviço de Radiologia do Hospital de Clínicas da Universidade Federal do Paraná (UFPR) e na Clínica de Diagnóstico por Imagem do Paraná - Cedip, Curitiba, PR.

1. Médico Radiologista do Hospital de Clínicas da UFPR e da Clínica de Diagnóstico por Imagem do Paraná - Cedip.

2. Médicos Residentes do Serviço de Radiologia do Hospital de Clínicas da UFPR.

3. Acadêmicos de Medicina e Estagiários do Departamento de Radiologia do Hospital de Clínicas da UFPR.

4. Médicos Radiologistas da Clínica de Diagnóstico por Imagem do Paraná - Cedip.

Endereço para correspondência: Dr. Arquimedes Artur Zorzetto. Clínica de Diagnóstico por Imagem do Paraná - Cedip. Rua Rafae Papa, 20, Jardim Social. Curitiba, PR, 82530-190. E-mail: aazorzetto@yahoo.com.br

Recebido para publicação em 6/9/2002. Aceito, após revisão, em $6 / 3 / 2003$. diagnóstico diferencial frente às afecções músculo-tendinosas do ombro.

\section{TÉCNICA DE EXAME}

No período de janeiro a dezembro de 2001, foram realizadas 34 ultra-sonografias da região do ombro no Serviço de Radiologia do Hospital de Clínicas da Universidade Federal do Paraná e na Clínica de Diagnóstico por Imagem do Paraná - Cedip, Curitiba, PR, em pacientes apresentando dor e dificuldade à mobilização do ombro, provenientes do ambulatório de ortopedia. As idades variaram de 34 a 75 anos (média de 55 anos), sendo $53 \%$ do sexo feminino e $47 \%$ do sexo masculino.

Foram empregados transdutores de alta freqüência (7,5-10 MHz), com análise comparativa dos dois ombros. Os exames foram realizados com o paciente em posição sentada. Foi inicialmente analisado o tendão do bíceps, nos planos longitudinal e transversal em posição neutra e rotação externa. A seguir foi analisado o tendão do músculo subescapular, também em rotação externa e nos planos longitudinal e transversal. Os pacientes foram então submetidos à manobra de rotação interna, hiperextensão e adução do braço, para análise do tendão dos músculos supra-espinhal, infraespinhal e redondo menor, nos planos longitudinal e transversal.

Os seguintes resultados foram observados: o exame foi normal em $23 \%$ dos pacientes (oito casos). Dos 26 casos alterados, observaram-se oito com ruptura total (30\%) (Figuras 1 a 5), cinco com ruptura parcial (19\%) (Figuras 6 a 11), dez com tendinopatia (38\%) (Figuras 11 a 13), dois com tenossinovite bicipital (7\%) (Figura 14), um com tendinopatia associada a artrite gotosa (3\%) (Figura 15), um pós-operatório (Figura 16) e um com luxação do 


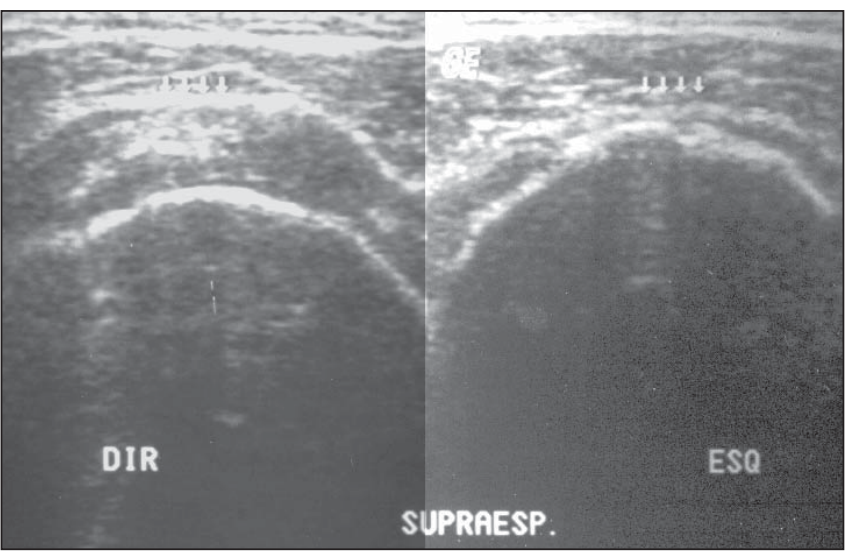

A

Figura 1. Sinal da "cabeça umeral careca". Ausência de visualização do tendão do supra-espinhal à esquerda, com irregularidade da cabeça do úmero (sinal direto de ruptura total). 0 tendão direito é mostrado para comparação (A,B). Complementação com artrografia, que demonstrou passagem do contraste para a bursa subacromial-subdeltóidea (C).

tendão do bíceps (Figura 17). Os casos de ruptura total tiveram o diagnóstico confirmado cirurgicamente.

\section{PRINCIPAIS PADRÕES DE IMAGEM}

O ombro doloroso é a segunda maior queixa relacionada ao sistema músculoesquelético, perdendo só para as lombalgias. Aproximadamente $60 \%$ das alterações do ombro estão ligadas a lesões do manguito rotador $^{(3)}$.

Com a introdução da ultra-sonografia, utilizando-se transdutores de alta resolução (7-12 MHz), ampliou-se muito a capacidade diagnóstica no exame do ombro e outras áreas do sistema músculo-esquelético. O largo campo de visão é útil para avaliar anormalidades superficiais e a resolução para estruturas próximas é maior ${ }^{(4)}$.

\section{ANATOMIA}

Entender a complexa anatomia tridimensional do manguito rotador é crucial para a adequada realização de um exame ultra-sonográfico do ombro.

O manguito rotador é composto por quatro músculos e seus tendões, sendo eles: músculos supra-espinhal, infra-espinhal, subescapular e redondo menor. $\mathrm{O}$ músculo subescapular é o mais anterior dos quatro. Origina-se na face costal da escápula, atravessa anteriormente a articulação gleno-umeral e se insere no tubérculo menor do úmero. O músculo supra-espi- nhal é o mais superior, originando-se na fossa supra-espinhal e se inserindo no tubérculo maior do úmero. O músculo infraespinhal origina-se na fossa infra-espinhal da escápula e se insere no tubérculo maior do úmero. O redondo menor é um pequeno músculo que pode estar fundido ao infra-espinhal. Outra estrutura muscular, rotineiramente examinada durante a ultra-sonografia do ombro, é o tendão da cabeça longa do bíceps, que se origina no tubérculo supraglenoidal, percorre o úmero lateral e anteriormente e sai da articulação pelo sulco intertubercular. $\mathrm{O}$ tendão bicipital e o manguito rotador são separados do processo acromial e do músculo deltóide por uma quantidade variável de gordura e pela bursa subdeltóidea-subacromial. A bursa promove a lubrificação local e auxilia na suavidade dos movimentos entre as estruturas vizinhas ${ }^{(5,6)}$.

\section{PROCEDIMENTO}

O paciente deve ser posicionado sentado, de preferência em um banco rotativo, que permite um fácil posicionamento de ambos os ombros. Deve-se iniciar pelo ombro menos sintomático ${ }^{(2)}$. A realização do exame nos dois lados permite a obtenção de imagens comparativas e a descoberta de lesões assintomáticas, que são bastante freqüentes em pacientes em faixa etária mais elevada. Deve-se sempre analisar a anatomia normal e a anormal através de dois planos ortogonais.

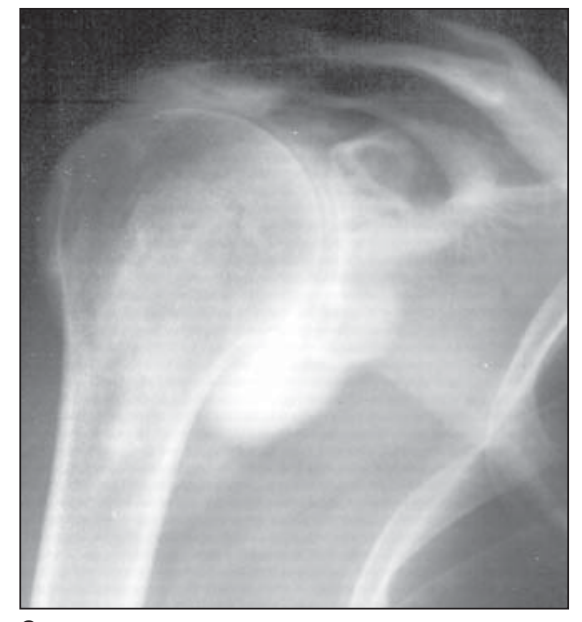

C
OHBRO ESP

As imagens transversais do tendão longo do bíceps são obtidas com o braço e antebraço do paciente apoiados na coxa e a palma da mão pronada. A fossa intertubercular serve como ponto anatômico de referência para diferenciar o tendão do músculo subescapular do supra-espinhal. A análise do tendão do bíceps deve ser feita em toda a sua extensão para a detecção de pequenas quantidades de fluido, uma vez que este é um indicador sensível da presença de fluido articular. O transdutor deve ser rodado em 90 graus para uma visão longitudinal do tendão e para assegurar-se da sua integridade ${ }^{(7)}$. O tendão do músculo subescapular é visualizado no plano transversal e proximalmente ao úmero.

O restante do exame é realizado com o paciente com o braço aduzido e hiperestendido e com o ombro em rotação interna moderada ${ }^{(\mathbf{1})}$. A análise longitudinal do músculo supra-espinhal é feita passandose o transdutor na circunferência da cabeça umeral. Movendo-se o transdutor mais 


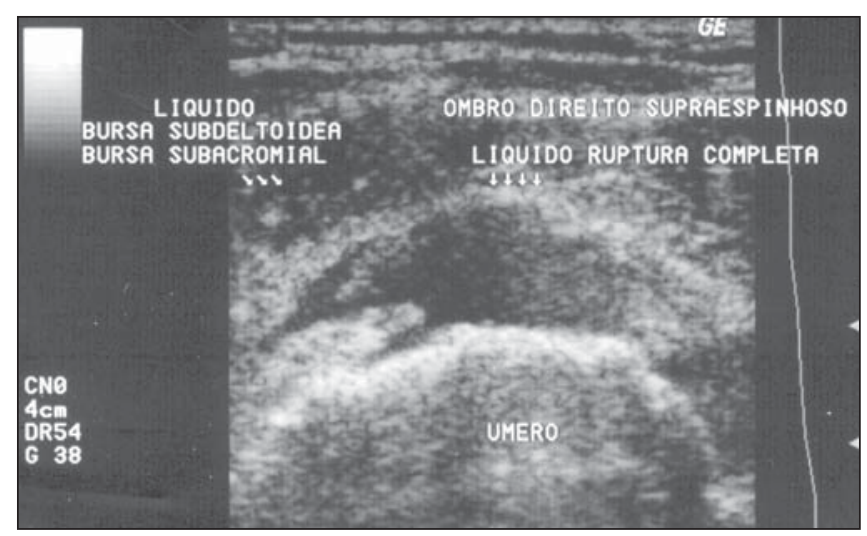

Figura 2

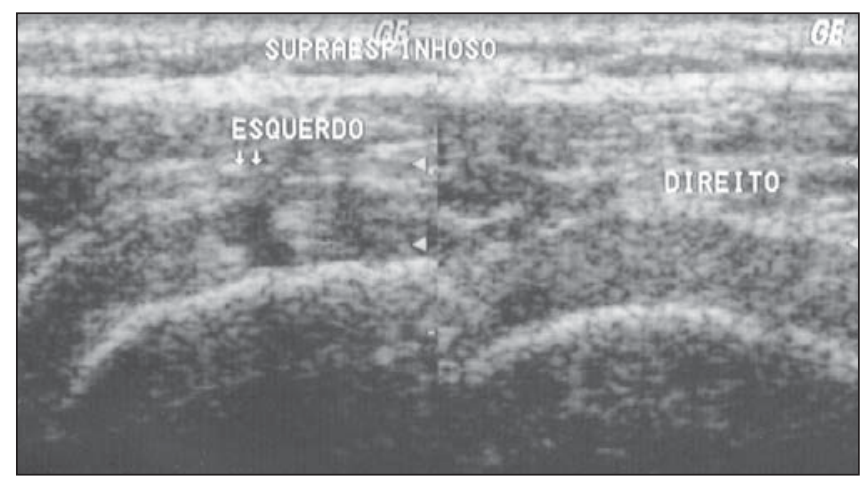

Figura 4

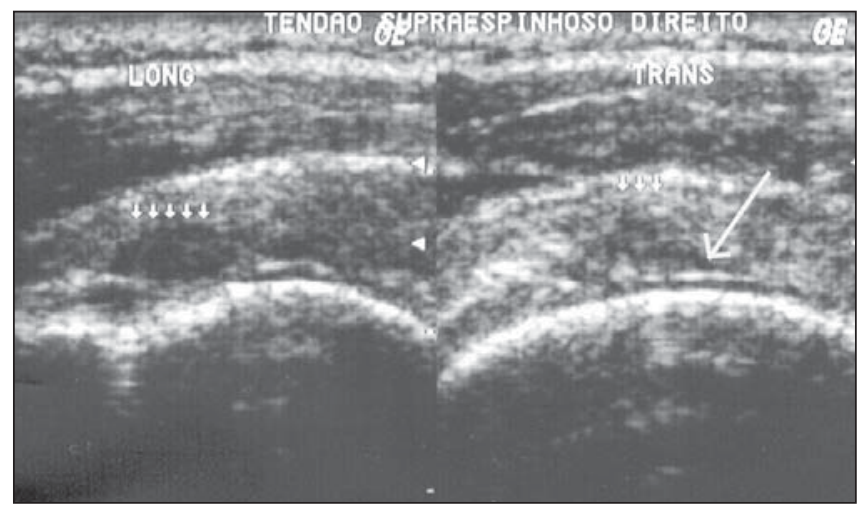

Figura 6

Figura 2. Ausência focal de visualização do tendão do supra-espinhal, notando-se, em sua topografia, coleção líquida limitada anteriormente e posteriormente pelas fibras retraídas do tendão roto (sinal direto de ruptura total).

Figura 3. Ausência focal do tendão do supra-espinhal, com visualização dos cotos anteriormente e posteriormente, devido às fibras retraídas (sinal direto de ruptura total).

Figura 4. Área de descontinuidade das fibras do tendão supra-espinhal preenchida por líquido (sinal direto de ruptura total) à esquerda. 0 tendão direito é mostrado para comparação.

Figura 5. Redução da espessura do tendão associada a insinuação da gordura subdeltóidea (sinal indireto de ruptura total) à direita. Exame comparativo com o lado esquerdo normal.

Figura 6. Hiperecogenicidade linear da cartilagem (seta longa) demonstrando o sinal da interface (sinal de ruptura parcial profunda).

Figura 7. Área hiperecogênica (seta longa) circundada por extenso halo hipoecogênico próximo à inserção do tendão no tubérculo maior (sinal de ruptura parcial intratendínea e profunda).

Figura 8. Área de descontinuidade das fibras, que se estende da superfície bursal para o interior do tendão (sinal de ruptura parcial superficial e intratendínea).

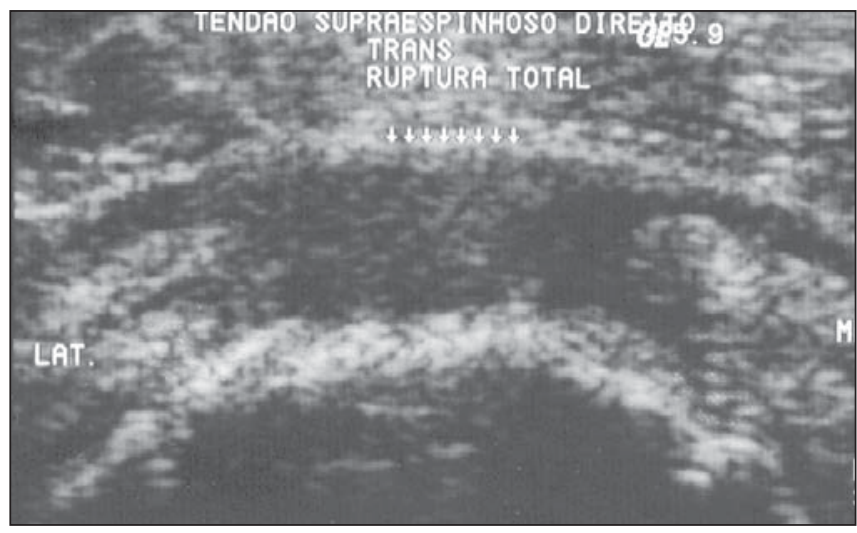

Figura 3

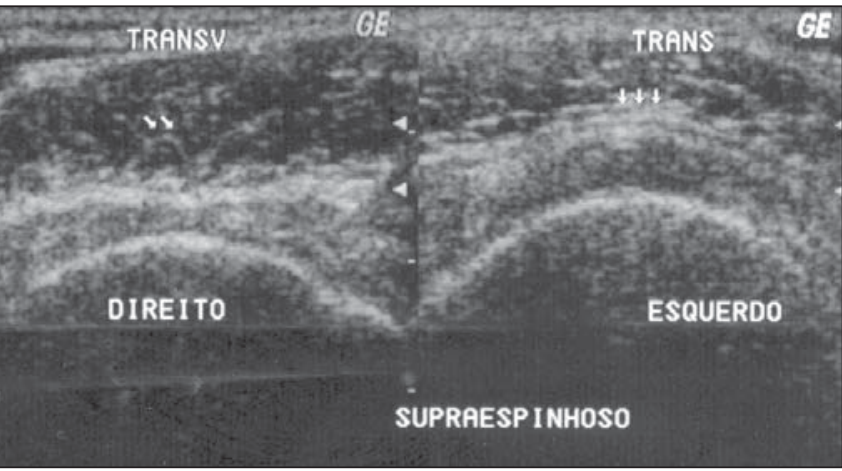

Figura 5
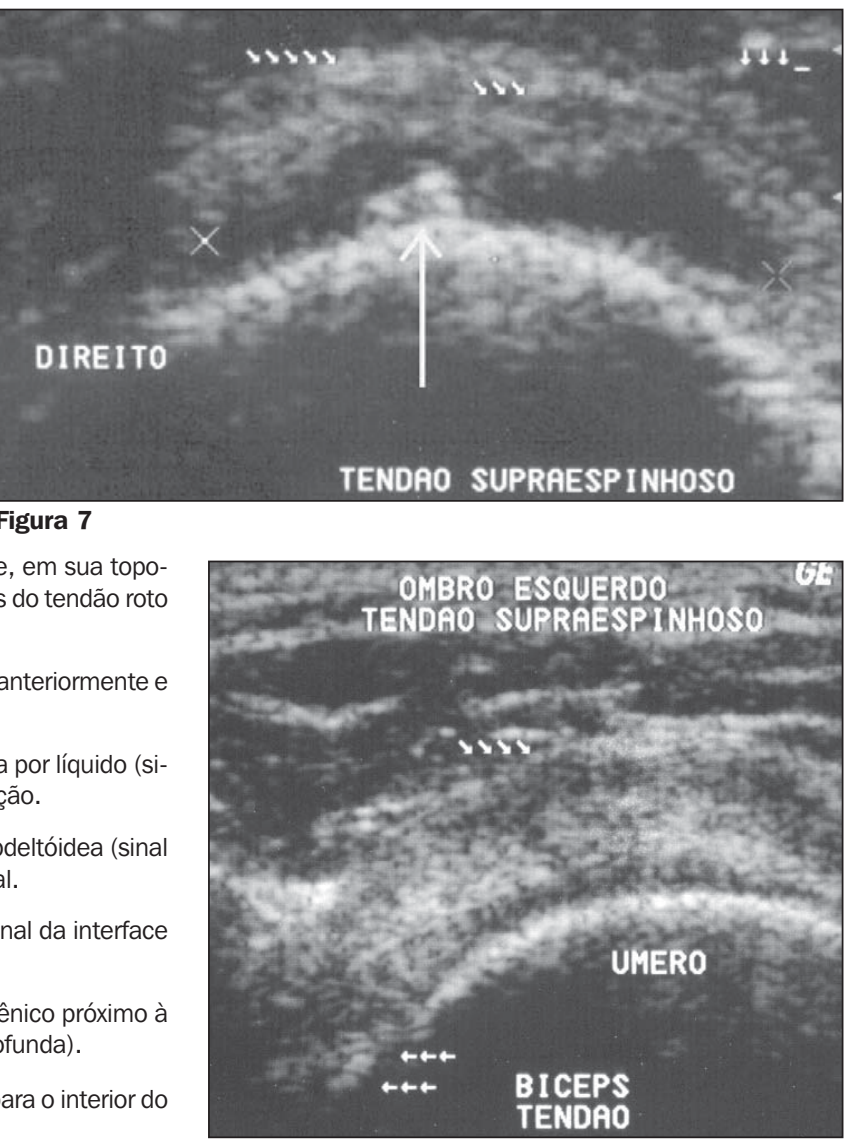

Figura 8 


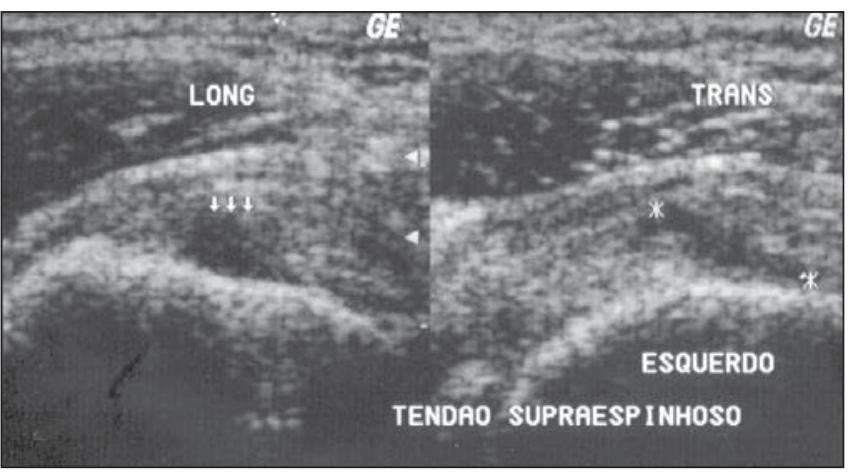

Figura 9. Área hipoecóica de contornos irregulares, que se estende da região intratendínea até a face articular (sinal de ruptura parcial intratendínea e profunda).

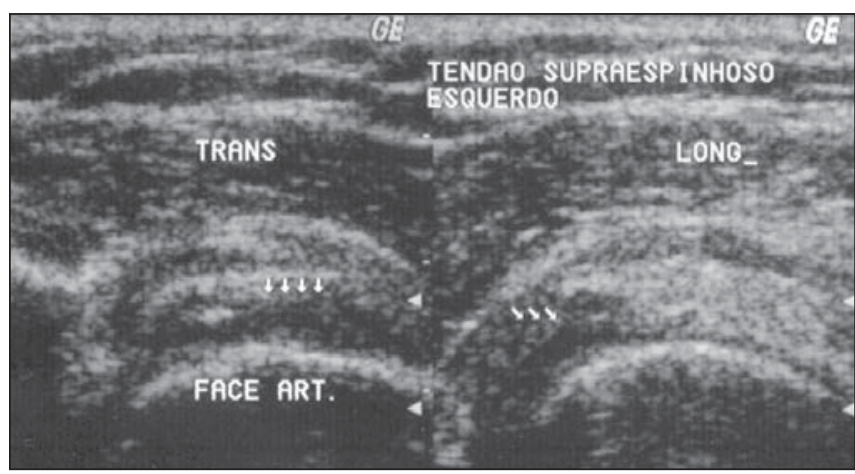

Figura 10. Área hipoecóica e irregular localizada junto à face articular do tendão (sinal de ruptura parcial profunda).

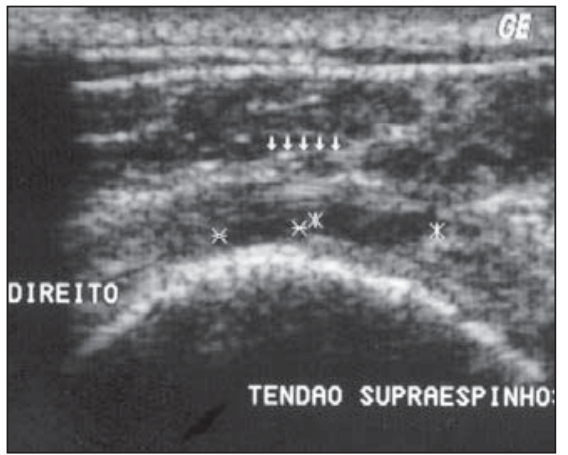

A

posteriormente, é possível a visualização do tendão dos músculos infra-espinhal e redondo menor. A visualização deve estender-se medialmente para se observar a região espinoglenoidal, os vasos e nervos supra-escapulares. Ao final do exame são feitas imagens coronais da junção acrômioclavicular, sendo recomendada a comparação entre ambos os $\operatorname{lados}^{(\mathbf{1 , 8})}$.

\section{ALTERAÇÕES PATOLÓGICAS}

As principais alterações patológicas que afetam o manguito rotador e seus achados ultra-sonográficos são descritos a seguir.

\section{Tendinopatia (tendinose/tendinite)}

A diferenciação ultra-sonográfica entre tendinose (degeneração) e tendinite (degeneração e processo inflamatório associado) é difícil, preferindo-se usar o termo tendinopatia $^{(3)}$. Caracteriza-se, ultra-sonograficamente, por:

- redução difusa da ecogenicidade do tendão (Figura 12);

- áreas hipoecóicas mal delimitadas acompanhando o sentido das fibras, as-

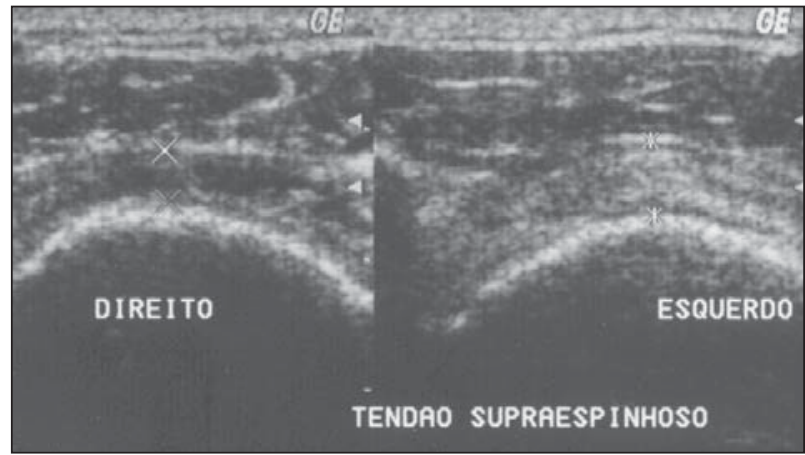

B

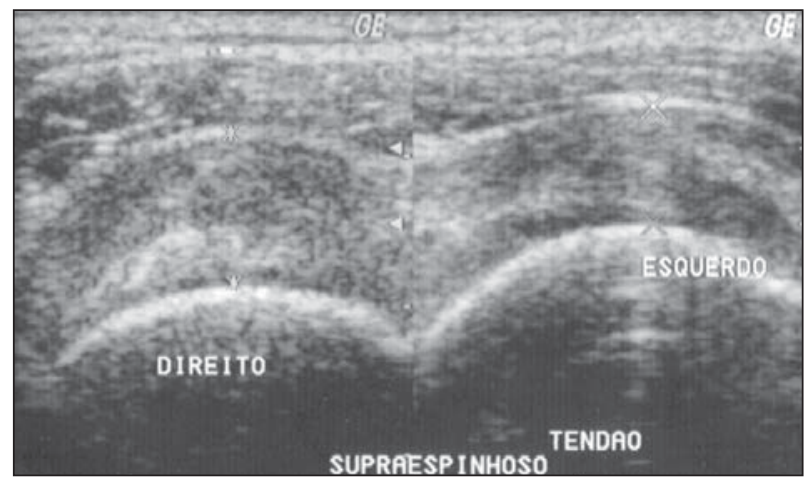

Figura 12. Tendão do músculo supra-espinhal espessado e discretamente hipoecóico em relação ao contralateral (tendinopatia).

sociadas ou não a aumento do diâmetro do tendão (Figura 12);

- calcificações distróficas caracterizadas por focos hiperecóicos com ou sem sombra acústica posterior (Figura 13).

\section{Ruptura parcial do manguito rotador}

As rupturas parciais são divididas em superficiais (junto à bolsa sinovial), intratendíneas e profundas (adjacentes à superfície articular). As lesões parciais são as mais difíceis de ser identificadas, causando controvérsias quanto à sua especificidade. Estudos mostram sensibilidade de $93 \%$ e
Figura 11. Tendão de espessura reduzida e contornos mal definidos, apresentando áreas hipoecóicas localizadas na região intratendínea e junto à superfície articular (tendinopatia crônica com sinais de ruptura parcial intratendínea e profunda) (A). Exame comparativo com o lado esquerdo normal (B). especificidade de $94 \%{ }^{(3)}$. Apresentam os seguintes padrões ultra-sonográficos:

- lesão hipoecogênica ou presença de pequena descontinuidade de fibras (Figuras 8, 9 e 10);

- lesão mista caracterizada por lesão hiperecóica circundada por halo hipoecóico (Figura 7).

\section{Ruptura total do manguito rotador}

A maioria das rupturas acomete o tendão do supra-espinhal, porém em cerca de metade dos casos outros tendões estão envolvidos. Podem ser diagnosticadas pela 


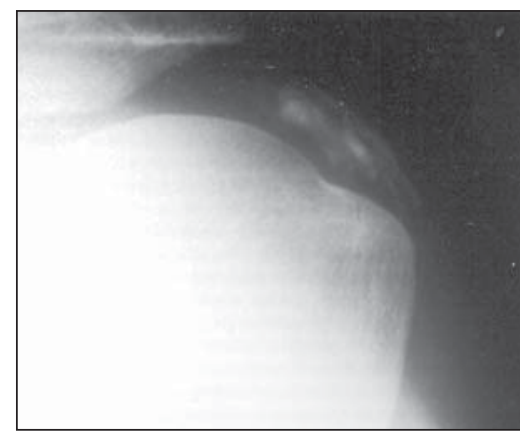

A

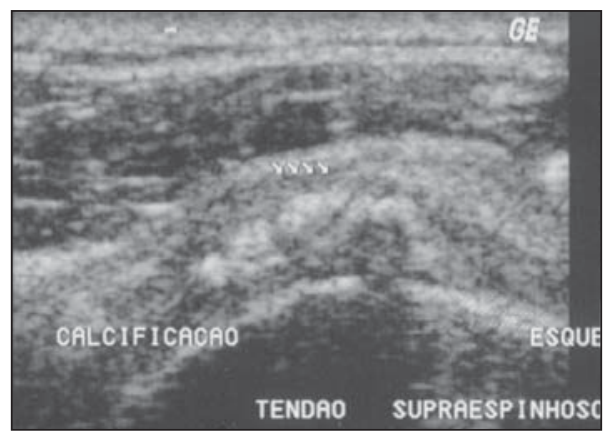

B

Figura 13. Radiografia demonstra calcificações grosseiras na topografia do manguito rotador (A). Ao estudo por ultra-sonografia o tendão do supra-espinhal apresenta-se espessado e com imagens hiperecóicas no interior (tendinopatia calcificada) (B).

ultra-sonografia, por meio de sinais diretos e indiretos. Os principais sinais diretos ou critérios maiores de ruptura são ${ }^{(3,9-11)}$.

— não visualização do tendão: observada nas rupturas extensas do manguito rotador, em que o tendão não é visualizado e a bursa subdeltóidea aproximase da superfície da cabeça do úmero (Figura 1);

— ausência focal do tendão: observada nas rupturas menores, em que pequena porção circunjacente ao tendão está preservada, podendo estar presente, no lugar, uma herniação da bolsa sinovial ou do músculo deltóide (Figuras 2 e 3);

- descontinuidade das fibras: observada quando pequenos defeitos na textura do manguito são preenchidos com fluido ou com tecido hiperecóico reativo ( $\mathrm{Fi}$ gura 4);

- alteração da ecogenicidade do tendão: a anormalidade difusa da ecogenicidade do manguito rotador não parece ser um dado confiável para o diagnóstico de ruptura. Já a anormalidade focal tem sido associada com rupturas pequenas parciais ou totais.

Dentre os sinais indiretos ou critérios menores de ruptura completa do mangui-

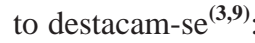

- coleções intra e extra-articulares: a visualização de fluido na bursa subacromial-subdeltóidea é o achado secundário mais confiável para o diagnóstico de ruptura do manguito rotador. Outros achados são líquido na articulação acrômio-clavicular (sinal de Geiser) e líquido na articulação gleno-umeral;

- espessamento da bursa subdeltóidea: normalmente a espessura da bursa sub- deltóidea é menor ou igual a $2 \mathrm{~mm}$. Nas grandes rupturas pode atingir até $5 \mathrm{~mm}$; — irregularidade da face óssea da articulação: somente recentemente tem sido citada como um importante achado asvada na maioria dos casos de rupturas médias e grandes do manguito;

— sinal da interface da cartilagem: ocorre pela interface entre a cartilagem articular e a região anecóica da ruptura total. Este sinal também pode ser observado em alguns casos de ruptura parcial profunda (Figura 6);

- contorno côncavo da gordura subdeltóidea: ocorre devido à insinuação do músculo deltóide nas áreas de rupturas médias e grandes (Figura 5).

\section{Tenossinovite do tendão da cabeça longa do bíceps braquial}

Embora o tendão da cabeça longa do bíceps não faça parte do manguito rotador, lesões desse tendão são encontradas em cerca de $40 \%$ dos casos associadas a ruptura do manguito.

Os principais achados ultra-sonográficos da tenossinovite são ${ }^{(\mathbf{4 , 6 , 1 2})}$ :

- espessamento, hipoecogenicidade e separação das fibras do tendão (Figura 14);

- líquido na bainha sinovial que circunda o tendão (Figura 14);

\section{Artropatias}

As artropatias inflamatórias, degenerativas ou por cristais apresentam-se como coleções de líquido na articulação ou na bursa subdeltóidea (Figura 15). sociado às rupturas (Figura 1). É obserdevido ao reforço acústico observado
A aparência da bursite é geralmente uma imagem moderadamente a fortemente ecogênica. É muito importante, nesses casos, a correlação clínica para sugerir ou reforçar o diagnóstico ${ }^{(6,12)}$.

\section{Alterações pós-cirúrgicas}

Os pacientes sintomáticos submetidos a acromioplastia, com ou sem reparo do manguito rotador, constituem uma dificuldade diagnóstica pela desestruturação anatômica normal. Na acromioplastia a porção ântero-inferior do acrômio é removida. Ultra-sonograficamente o acrômio apresenta-se pontiagudo e, como a parte inferior é removida, uma maior porção do músculo supra-espinhoso pode ser vista. O reparo cirúrgico do manguito rotador, habitualmente, gera imagens características. Os tendões do manguito são reimplantados em uma fenda, perpendicularmente ao eixo do supra-espinhal. A fenda apresenta-se como um defeito no contorno umeral, mais bem visualizado com o transdutor longitudinalmente ao supra-espinhal. O exame do ombro com o braço em extensão e rotação interna pode ser necessário para a visualização adequada do local de reimplantação do tendão. É importante salientar que a aparência sonográfica do tendão não retorna ao normal nos pacientes operados. Os tendões, especialmente do supra-espinhal, são geralmente ecogênicos e menos espessos quando comparados com o lado contralateral $^{(\mathbf{1 3 , 1 4 )}}$ (Figura 16).

\section{Outras afecções}

Embora o ultra-som não seja o melhor método para se analisar o osso, osteófitos podem ser vistos e fraturas podem ser detectadas. Pode ainda ser usado nas lesões que causam instabilidade, sendo a medida da distância do deslocamento gleno-umeral de grande valia. As anormalidades ligamentares também podem ser analisadas e apresentam vantagem sobre a ressonância magnética em relação ao custo e à facilidade de realização ${ }^{(\mathbf{1 2})}$.

\section{CONCLUSÃO}

O ombro doloroso é afecção bastante freqüente e que tem muitas causas. Atualmente, a ultra-sonografia com transdutores de alta resolução apresenta uma melhor 


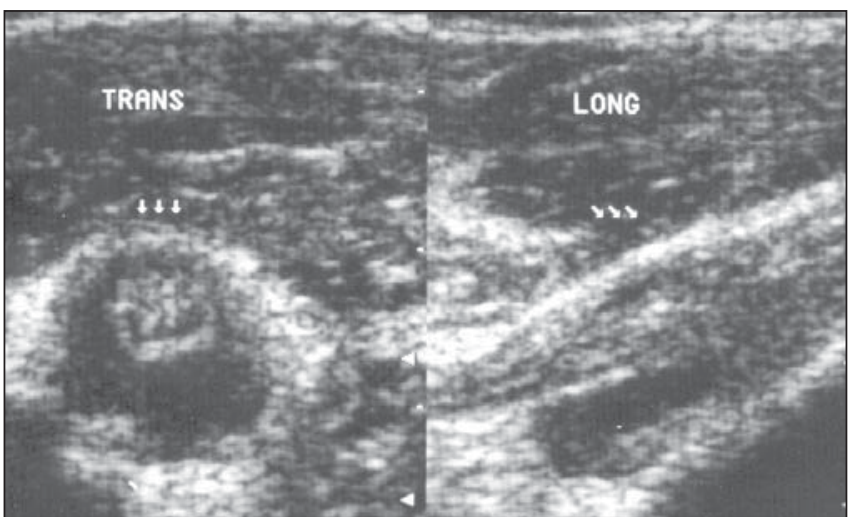

Figura 14

Figura 14. Bíceps espessado e hipoecóico, envolto por grande quantidade de líquido sinovial (tenossinovite bicipital).

Figura 15. Grande aumento da espessura do tendão supra-espinhal, com contornos mal definidos, heterogêneo, contendo imagens ecogênicas com sombra acústica no interior (tendinopatia por artrite gotosa).

Figura 16. Pós-operatório de acromioplastia há seis meses demonstrando tendão supra-espinhal esquerdo com espessura diminuída, heterogêneo e com indefinição dos contornos superiores. O tendão direito normal é demonstrado para comparação.

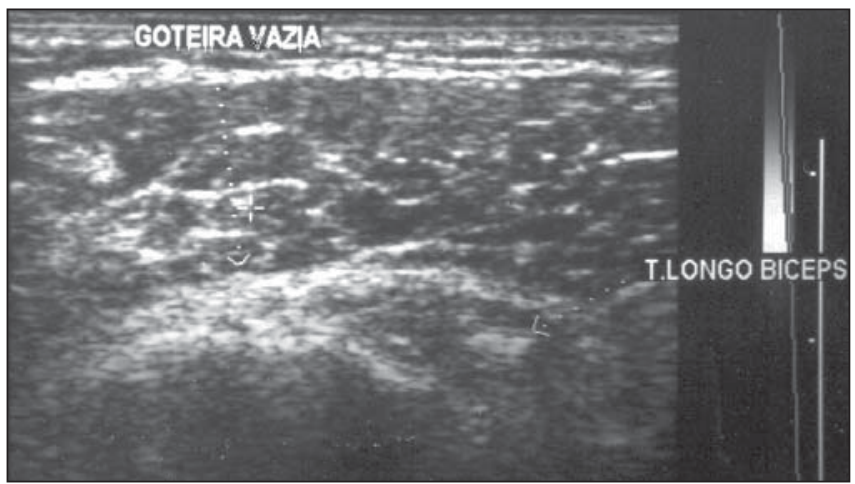

A

Figura 17. Deslocamento medial do tendão longo do bíceps, com visualização da goteira bicipital vazia (A,B).

diferenciação e acompanhamento da evolução das lesões do ombro. Além disso, é o único método que observa funcionalmente o manguito, com menores custos e maior acessibilidade que os outros métodos, sendo em muitas instituições, assim como na nossa, a modalidade de escolha para a avaliação inicial do ombro. Por ser um método operador dependente, o conhecimento da anatomia normal e das lesões músculo-tendinosas torna-se imperativo para o ultra-sonografista, atualmente.

\section{REFERÊNCIAS}

1. Crass JR, Craig EV, Feinberg SB. The hyperextended internal rotation view in rotator cuff ultra-

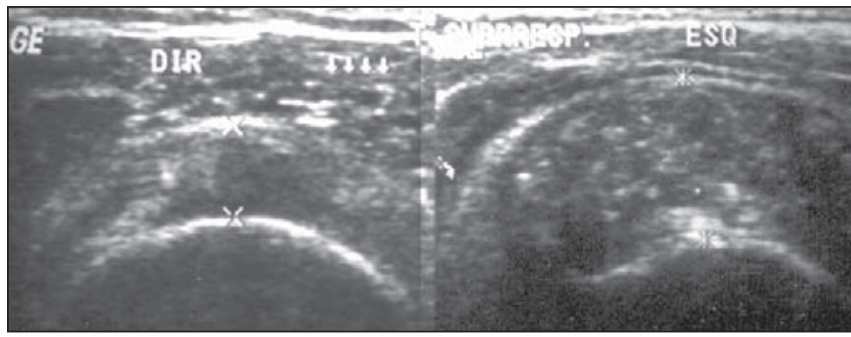

Figura 15

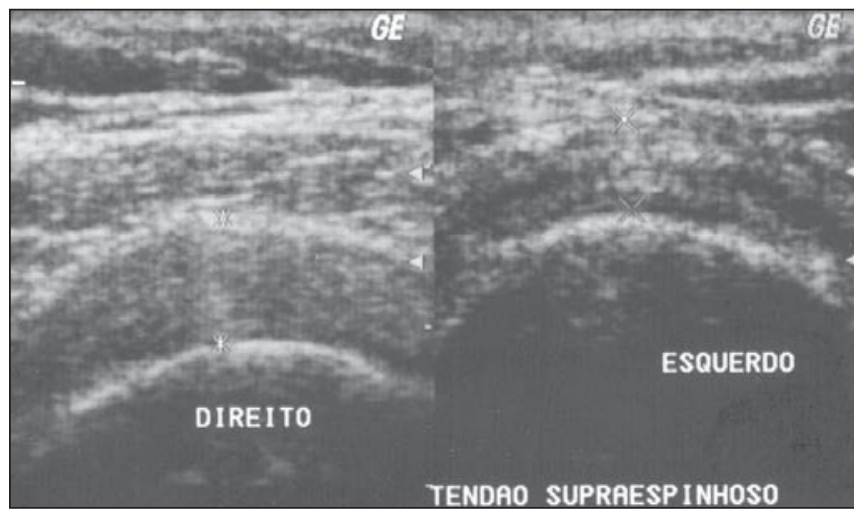

Figura 16

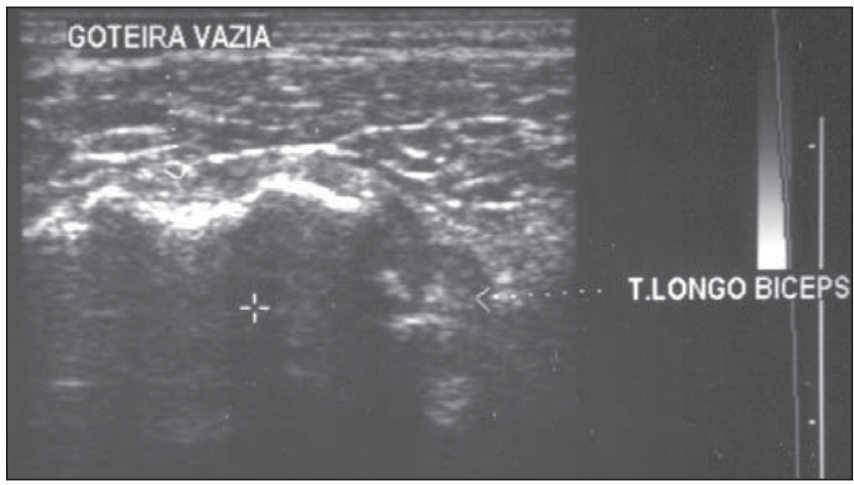

B sonography. J Clin Ultrasound 1987;15:416-20.

2. van Holsbeeck MT, Kolowich PA, Eyler WR, et al. US depiction of partial-thickness tear of the rotator cuff. Radiology 1995;197:443-6.

3. Sernik RA, Rodrigues Jr AJ, Rodrigues CJ. Ombro. In: Sernik RA, Cerri GG. Ultra-sonografia do sistema musculoesquelético. São Paulo: Sarvier, 1999:3-50.

4. Middleton WD. Ultrasonography of the shoulder. Radiol Clin Am North 1992;30:927-40.

5. Prescher A. Anatomical basics, variations, and degenerative changes of the shoulder joint and shoulder girdle. Eur J Radiol 2000;35:88-102.

6. Allen GM, Wilson DJ. Ultrasound of the shoulder. Eur J Ultrasound 2001;14:3-9.

7. Ptasznik R, Hennessy O. Abnormalities of the biceps tendon of the shoulder: sonographic findings. AJR 1995;164:409-14.

8. Wallny TA, Schild RL, Schulze-Bertelsbeck D, Hansmann ME, Kraft CN. Three-dimensional ultra- sonography in the diagnosis of rotator cuff lesions. Ultrasound Med Biol 2001;27:745-9.

9. Middleton WD. Status of rotator cuff sonography. Radiology 1989;173:307-9.

10. Sonnabend DH, Hughes JS, Giuffre BM, Farrell R. The clinical role of shoulder ultrasound. Aust NZ J Surg 1997;67:630-3.

11. Chang CY, Wang SF, Chiou HJ, Ma HL, Sun YC, Wu HD. Comparison of shoulder ultrasound and MR imaging in diagnosing full-thickness rotator cuff tears. Clin Imaging 2002;26:50-4.

12. Peetrons P, Rasmussen OS, Creteur V, Chhem RK Ultrasound of the shoulder joint: non "rotator cuff" lesions. Eur J Ultrasound 2001;14:11-9.

13. Mack LA, Nyberg DA, Matsen FR 3rd, Kilcoyne RF, Harvey D. Sonography of the postoperative shoulder. AJR 1988;150:1089-93.

14. Crass JR, Craig EV, Feinberg SB. Sonography of the postoperative rotator cuff. AJR 1986;146:561-4. 